\title{
Combined analysis of cell growth and apoptosis-regulating proteins in HPVs associated anogenital tumors
}

\author{
Tsuyoshi Mitsuishi*1, Yukie Iwabu2, Kenzo Tokunaga22, Tetsutaro Sata2, Takehiko Kaneko³, Kuniaki Ohara4,

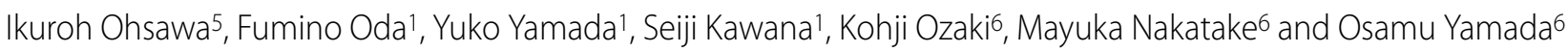

\begin{abstract}
Background: The clinical course of human papillomavirus (HPV) associated with Bowenoid papulosis and condyloma acuminatum of anogenital tumors are still unknown. Here we evaluated molecules that are relevant to cellular proliferation and regulation of apoptosis in HPV associated anogenital tumors.

Methods: We investigated the levels of telomerase activity, and inhibitor of apoptosis proteins (IAPs) family (C-IAP1, CIAP2, XIAP) and c-Myc mRNA expression levels in 20 specimens of Bowenoid papulosis and 36 specimens of condyloma acuminatum in anogenital areas. Overall, phosphorylated (p-) AKT, p-ribosomal protein S6 (S6) and p-4Ebinding protein 1 (4EBP1) expression levels were examined by immunohistochemistry in anogenital tumors both with and without positive telomerase activity.

Results: Positive telomerase activity was detected in $41.7 \%$ of Bowenoid papulosis and $27.3 \%$ of condyloma acuminatum compared to normal skin $(p<0.001)$. In contrast, the expression levels of Bowenoid papulosis indicated that c-IAP1, c-IAP2 and XIAP mRNA were significantly upregulated compared to those in both condyloma acuminatum samples ( $p<0.001, p<0.001, p=0.022$, respectively) and normal skin $(p<0.001, p=0.002, p=0.034$, respectively). Overall, $30 \%$ of Bowenoid papulosis with high risk HPV strongly promoted IAPs family and c-Myc but condyloma acuminatum did not significantly activate those genes. Immunohistochemically, p-Akt and p-S6 expressions were associated with positive telomerase activity but not with $\mathrm{p}-4 \mathrm{EBP} 1$ expression.
\end{abstract}

Conclusion: Combined analysis of the IAPs family, c-Myc mRNA expression, telomerase activity levels and p-Akt/p-S6 expressions may provide clinically relevant molecular markers in HPV associated anogenital tumors.

\section{Background}

Telomerase is a ribonucleoprotein reverse transcriptase (RT) complex that adds telomeric TTAGGG repeat sequences to chromosomes by using an intrinsic RNA component as template [1,2]. Human telomerase consists of RNA components and a catalytic subunit of human telomerase RT (hTERT), and is coimmunoprecipitated with Akt kinase, heat shock protein 90, the mammalian target of rapamycin (mTOR), and p70 ribosomal protein S6 kinase 1 (S6K1) [3]. Transcription factors c-Myc, SP1,

* Correspondence: tmitsu@nms.ac.jp

1 Department of Dermatology, Nippon Medical School, 1-1-5 Sendagi, Bunkyou-ku, Tokyo, 113-8603, Japan

Full list of author information is available at the end of the article estrogen receptor, E2F-1, WT-1, NFKB and MZF-2 are involved in regulation of hTERT gene expression [4]. Telomerase activity (TA), an indicator of cellular immortalization, is considered to at least partly responsible for the unlimited replication seen in immortalized cells $[1,5]$. Previous studies have shown that malignant skin neoplasias, including melanoma, exhibit high levels of TA compared to benign skin conditions [6]. High levels of TA in such malignant cells may act to maintain stable telomere lengths [7].

In general, cutaneous tumors of the anogenital area are usually associated with human papillomaviruses (HPVs). High and low risk HPV types are usually detected in Bowenoid papulosis (BP) and condyloma acuminatum 
(CA), respectively. BP is a rare skin neoplasia, which is found in the anogenital area as multifocal papular lesions. In contrast, CA occasionally occurs as pigmented nodules or papules in the anogenital area, resulting sometimes in its misdiagnosis as BP [8]. Overall, high and low risk HPV types were sometimes found in BP $[9,10]$. Recently, E6 oncoproteins belonging to high risk HPV types were shown to increased TA in epithelial cells, predominantly by inducing transcription of the hTERT gene [11]. In BP and CA, some anogenital tumors show rapid growth and mitosis, while others show spontaneous remission. Therefore, it is clinically difficult to determine whether it is necessary to treat HPV associated anogenital tumors.

The phosphorylated (p-) proteins associated with cell signaling pathways, e.g., Akt, 4E-binding protein 1 (4EBP1) and ribosomal protein S6 (S6), provide proliferative signals, promote survival and regulate protein synthesis [12]. Among these proteins, protein kinase Akt is activated by phosphorylation of threonine 308 , and serine 473 has been shown to be important in mediating cell proliferation and inhibiting apoptosis in several tissues and cancers $[13,14]$. The Akt activates many downstream factors, including mTOR, which in turn activates 4EBP1 and $\mathrm{p} 70 \mathrm{~S} 6 \mathrm{~K} 1$. The 4EBP1 and p70S6K1 play a critical role in controlling ribosomal protein synthesis during cell proliferation $[15,16]$ through the phosphorylation of eukaryotic initiation factor $4 \mathrm{E}$ and S6, respectively. However, expression of p-AKT, p-S6 and p-4EBP1 in anogenital tumors has not been previously reported.

Recently, inhibitors of apoptosis protein (IAP) family members, e.g., c-IAP1, c-IAP2 and XIAP, were reported to act as tumor markers and were used as prognostic factors for estimating the survival of cancer patients. There is a large body of data demonstrating elevated expression of IAP proteins in many human cancers [17-19]. Among them, cervical cancer cells with high risk HPV types have been investigated for the expression of IAPs family $[20,21]$, however, there are no reports about the expression of those genes of HPV associated anogenital tumors. The majority of HPV associated tumor cells possess active TA, and a combination of active TA and high risk HPV oncogene proteins E6 and E7 contributes to the immortalization of primary epithelial cells. The E6 of HPV directly interacts with c-Myc, and the complex activates hTERT expression [11]. Recently, the transcription of c-IAP2, a member of the IAP protein family, was shown to be significantly upregulated by E6 and E7 oncoproteins in cells infected with high risk type HPV 16, but not in cells infected with low risk type HPV 6. Among IAPs family members, c-IAP2 is related to hTERT protein and promotes hTERT as well as c-Myc activity in E6 of HPV 16 [22]. To evaluate molecules relevant to cellular proliferation and immortalization, we examined the expression of the IAPs family members and c-Myc in CA and BP by real time RT-PCR. In addition, we present the TA level and correlate a positive TA with the frequency of p-Akt, p-S6 and p-4EBP1 expression in these tumors.

\section{Methods}

\section{Patients and tissues samples}

A total of 74 samples (36 CA, $20 \mathrm{BP}$, and 18 normal skin (NS)) obtained from 74 Japanese patients were examined in the current study. Biopsy or surgical specimens were collected at the Department of Dermatology, Nippon Medical School, Japan. Initially, 12 BP and 22 CA specimens were collected and were immediately placed in liquid nitrogen and stored at $-80^{\circ} \mathrm{C}$ until proteins and DNAs extraction. A second portion of each samples was fixed in $10 \%$ buffered formalin solution and embedded in paraffin for histopathologic examination, and immunohistochemistry. Eight $\mathrm{BP}$ and $14 \mathrm{CA}$ samples were collected to examine the expression of IAPs family and c-Myc by real time RT-PCR. In addition, initial remained 2 BP and 1 CA frozen samples were used for real time RT-PCR. Samples of NS were collected from a remainder of non sunexposed skin, which was used as donor skin for performing a skin graft. None of the donor patients had a history of lymphatic disorders or exhibited active atopic dermatitis. Informed consent was obtained from each patient, and the study was approved by the Ethical Committee at Nippon Medical School and National Institute of Infectious Diseases.

\section{Preparation of tissue extracts}

The frozen tissues consisting of 12 samples out of $20 \mathrm{BP}$, 22 samples out of $36 \mathrm{CA}$, and 14 samples out of 18 normal skin were added in ice lysis buffers and homogenized gently $\{(105$ cells $/ 20 \mu \mathrm{l})$ in ice-cold lysis buffer $[10 \mathrm{mM}$ tris- $\mathrm{HCl}$ (pH 7.5), $1 \mathrm{mM} \mathrm{MgCl} 21 \mathrm{mM}$ EDTA, $0.1 \mathrm{mM}$ PMSF, 5 mM $\beta$-mercaptoethanol, 0.5\% 3-[(3-Cholamidopropyl)dimethylammonio]-1-propane-sulfonate

(CHAPS), and $10 \%$ glycerol]\}. The suspension was incubated for $30 \mathrm{~min}$ on ice and then centrifuged at 100,000 g for $30 \mathrm{~min}$ at $4^{\circ} \mathrm{C}$. The supernatant was removed and the protein concentration was determined by the Bradford assay (Bio-Rad, Hercules, CA).

\section{Nonradioisotope telomere repeat amplification protocol (TRAP) assay}

Telomerase activity (TA) was assayed by the TRAP method in a total volume of $25 \mu \mathrm{l}$, as previously described $[5,23,24]$. In brief, aliquots of untreated cell extract were incubated with $0.1 \mu \mathrm{g}$ of TS oligonucleotide primer (5'AATCCGTCGAGCAGAGTT-3') for $20 \mathrm{~min}$ at $22^{\circ} \mathrm{C}$ in the following reaction mixture: $20 \mathrm{mM}$ Tris- $\mathrm{HCl}(\mathrm{pH} 8.3)$, $1.5 \mathrm{mM} \mathrm{MgCl} 2,63 \mathrm{mM} \mathrm{KCl}, 0.005 \%$ Tween-20, $1 \mathrm{mM}$ EDTA, $50 \mu \mathrm{M}$ dNTPs, $1 \mu \mathrm{g}$ of T4 gene 32 protein (Roche, 
Mannheim, Germany), and $0.1 \mathrm{mg} / \mathrm{ml}$ BSA. Following elongation of the TS oligonucleotide primer by telomerase, the mixture was incubated at $95^{\circ} \mathrm{C}$ for $5 \mathrm{~min}$ prior to the addition of 5 units of Taq polymerase and $0.1 \mu \mathrm{g}$ CX oligonucleotide primer (5'-CCCTTACCCTTACCCTTACCCTAA-3'). The elongated products were amplified by PCR $\left(30\right.$ cycles at $94^{\circ} \mathrm{C}$ for $30 \mathrm{~s}, 50^{\circ} \mathrm{C}$ for $30 \mathrm{~s}$, and $72^{\circ} \mathrm{C}$ for $60 \mathrm{~s}$ ). One-fourth of each reaction product was then analyzed by electrophoresis in $1 \times$ Tris-glycine on $12.5 \%$ polyacrylamide nondenaturing gels and visualized with SYBR Green DNA stain (BMA Rockland, ME, USA). Internal telomerase assay standard (ITAS) was used as an internal control [25].

\section{Quantification of enzyme activity}

Quantification of enzyme activity in samples was determined using NIH imaging software [25]. In brief, the signal intensity of each band on the TRAP ladders was measured individually. These values were compared with TRAP products obtained with known amounts of control extract, assayed in parallel. The relative specific TA of each sample is expressed as a percentage of the specific activity of the control extracts. An extract of EB virus transformed B cell lines (Namalva cells) was used as a positive control. We estimated that more than $20 \%$ of relative TA value mean having significant enzymatic activity in individual sample compared with Namalva cells and normal skin samples by calculating with $\mathrm{NIH}$ imaging soft ware.

\section{Real Time RT-PCR and gene expression analysis}

Real time RT-PCR was performed in order to evaluate the differences in the expression of IAPs family members (cIAP1, c-IAP2, X-IAP) and c-Myc between BP, CA and NS. The frozen tissues (10 of $20 \mathrm{BP}$ samples, 15 of $36 \mathrm{CA}$ samples, and 4 of 18 NS samples) were used for real time RT-PCR and gene expression analysis. The mRNA transcripts of the IAPs family members and c-Myc were quantified using the quantitative kinetic reverse transcription PCR methodology (Applied Biosystems, Foster City, CA) and Taqman chemistry (Roche Applied Science, Penzberg, Germany). All expression levels were normalised to the expression of the housekeeping gene, GAPDH. Total RNA was extracted from the skin samples using an RNAqueous Kit (Ambion, Austin, TX) and treated with TURBO DNA-free (Ambion, Austin, TX) according to the manufacturer's protocols. The prepared RNAs were subjected to real time PCR using an Mx3005P thermocycler (Strategene, San Diego, CA) and a QuantiTect Multiplex RT-PCR Kit (Qiagen, Valencia, CA) [26]. Plasmids were assayed along with the tissue RNAs and used to construct standard curves. The specific probes and primers that were used are shown in Table 1.

\section{Immunohistochemistry}

A total of $22 \mathrm{CA}$ ( 5 with and 17 without TA) samples and 12 BP (5 with and 7 without TA) samples were analysed for telomerase activity were also examined immunohistochemically in order to compare the expression of $\mathrm{p}$-Akt thr308, p-S6 and p-4E binding protein 1(4EBP1). Rabbit polyclonal antibodies against p-Akt thr308 (Santa Cruz Biotechnology, Santa Cruz, CA, \#sc-16646-R, dilution1:400), p-S6 ser235/236 (Cell Signaling Technology, Danvers, MA, \#2211, 1:200), and p-4EBP1 thr70 (Cell Signaling Technology, \#9455, 1:50) were used. Immunohistochemistry was performed on the tissue sections from tumours with high or low TA that were mounted on aminopropyltriethoxysilane-treated slides (Matsunami Glass Ind., LTD., Osaka, Japan), as previously described [27].

\section{Immunohistochemical evaluation}

The stained sections were independently examined by two of the authors (F.O. and Y. Y.). The labelling index of p-Akt thr308, p-S6, and p-4EBP1 was determined by assessing the number of stained cells within the relevant area of a selected section containing more than 50 intraepidermal cells, and at least 4 random microscopic fields at $200 \times$ magnification were evaluated. After counting both immunoreactive cells and the total number of intraepidermal cells, the average percentage of immunoreactive cells was calculated without knowledge of the clinical data. The percentage of positive cells was arbitrarily scored as follows: $0,<30 \% ; 1,30 \%$ to $60 \% ; 2,>60 \%$ [28].

\section{Western blot}

Western blot analysis and reverselysate protein rays were performed in anogenital tumors samples. Proteins were resolved on a polyacrylamide gel and transferred to a polyvinylidene difluoride (PVDF) membrane (Bio-Rad, Hercules, CA). The membrane was incubated with the primary antibodies and then the HRP-conjugated antirabbit IgG antibody. Immunoreactive bands were visualised with the ECL Plus Detection Reagent according to the manufacturer's protocol (GE Healthcare Bio-Sciences, Piscataway, NJ).

\section{Detection of HPV DNA and typing}

Available frozen tissues from $10 \mathrm{BP}$ and $10 \mathrm{CA}$ samples were digested with proteinase $\mathrm{K}(100 \mathrm{mg} / \mathrm{ml})$ in the presence of $0.5 \%$ SDS for $2 \mathrm{~h}$ at $65^{\circ} \mathrm{C}$, and extracted with phenol-chloroform-isoamyl alcohol. The DNAs were then precipitatedin ethanol as previously described [29]. Total cellular DNA was used for PCR amplification using $\mathrm{L} 1 \mathrm{C} 1 / \mathrm{L} 1 \mathrm{C} 2(\mathrm{C} 2 \mathrm{~m})$ primers [30]. The primer sets are able to amplify majority of mucosal HPV types including types 6 and 16. The HPV type was determined by comparing the restriction fragment length polymorphism 
Table 1: Sequences of specific probes and primers for real time RT-PCR

\begin{tabular}{|c|c|c|c|c|c|c|c|}
\hline Gene & Application & Sequence & Length (bp) & $5 '$ & $3{ }^{\prime}$ & $\operatorname{Tm}\left({ }^{\circ}\right)$ & $\begin{array}{c}\text { Genebank } \\
\text { accession } \\
\text { number }\end{array}$ \\
\hline \multirow[t]{3}{*}{ GAPDH } & $\mathrm{P}$ & $\begin{array}{l}\text { AAC AGC GAC ACC CAC } \\
\text { TCC TCC ACC }\end{array}$ & 24 & FAM & BHQ1 & 67.4 & $\underline{\text { NM } 002046}$ \\
\hline & $\mathrm{F}$ & $\begin{array}{l}\text { ACC AGG TGG TCT CCT } \\
\text { CTG AC }\end{array}$ & 20 & & & 58.5 & \\
\hline & $\mathrm{R}$ & $\begin{array}{l}\text { TGT AGC CAA ATT CGT } \\
\text { TGT CAT ACC }\end{array}$ & 24 & & & 58.6 & \\
\hline \multirow[t]{3}{*}{ C-IAP1 } & $\mathrm{P}$ & $\begin{array}{l}\text { AGG AAA TGC TGC GGC } \\
\text { CAA CAT CTT CA }\end{array}$ & 26 & ROX & BHQ2 & 66.8 & $\underline{\text { NM } 001166}$ \\
\hline & $\mathrm{F}$ & $\begin{array}{l}\text { GAG AGA ACT GAT TGA } \\
\text { TAC CAT TाT GG }\end{array}$ & 26 & & & 57.6 & \\
\hline & $\mathrm{R}$ & $\begin{array}{l}\text { AGA CCT GAA ACA TCT } \\
\text { TCT GTT GG }\end{array}$ & 23 & & & 57.3 & \\
\hline \multirow[t]{3}{*}{ C-IAP2 } & $\mathrm{P}$ & $\begin{array}{l}\text { TCC GTC AAG TTC AAG } \\
\text { CCA GTT ACC CTC A }\end{array}$ & 28 & Cy5 & BHQ3 & 67.2 & NM 001165 \\
\hline & $\mathrm{F}$ & $\begin{array}{l}\text { CTT GAT AAG AAT TAA } \\
\text { AGG ACA GGA GTT C }\end{array}$ & 28 & & & 58.0 & \\
\hline & $\mathrm{R}$ & $\begin{array}{l}\text { TGG GCT GTC TGA TGT } \\
\text { GGA TAG }\end{array}$ & 21 & & & 57.5 & \\
\hline \multirow[t]{3}{*}{ XIAP } & $\mathrm{P}$ & $\begin{array}{l}\text { CAG TGA AGA CCC TTG } \\
\text { GGA ACA ACA TGC T }\end{array}$ & 28 & HEX & BHQ1 & 66.7 & $\underline{\text { NM } 001167}$ \\
\hline & $\mathrm{F}$ & $\begin{array}{l}\text { GGA GGA GGG CTA ACT } \\
\text { GAT TGG }\end{array}$ & 21 & & & 58.1 & \\
\hline & $\mathrm{R}$ & $\begin{array}{l}\text { TAT TCT TGT CCC TTC } \\
\text { TGT TCT AAC AG }\end{array}$ & 26 & & & 57.9 & \\
\hline \multirow[t]{3}{*}{ c-Myc } & $\mathrm{P}$ & $\begin{array}{l}\text { CCA CCA CCA GCA GCG } \\
\text { ACT CTG AGG A }\end{array}$ & 25 & HEX & BHQ1 & 69.0 & NM 002467 \\
\hline & $\mathrm{F}$ & $\begin{array}{l}\text { GGT GCT CCA TGA GGA } \\
\text { GAC AC }\end{array}$ & 20 & & & 58.1 & \\
\hline & $\mathrm{R}$ & $\begin{array}{l}\text { CCA GCA GAA GGT GAT } \\
\text { CCA GAC }\end{array}$ & 21 & & & 58.7 & \\
\hline
\end{tabular}


(RFLP) pattern of the amplified sequences with those deduced from sequences of known HPV types in Genbank or EMBL Databank [30].

\section{Statistical methods}

The differences between the cases were assessed using $X^{2}$ analyses to compare categorical variables and the MannWhitney $U$ test to compare continuous measures. Statistical analysis was carried out using the SPSS software package (SPSS Inc., version 17.0, Chicago, IL, USA). A two-sided test with a significance level of 0.05 was used to determine statistical significance for all analyses.

\section{Results}

\section{Histopathologic examination}

Histopathologic examination of 20 BP showed the presence of several dyskeratotic keratinocytes in a thickened epidermis with hyperchromatic nuclei. There were no significant histopathologic differences in $20 \mathrm{BP}$. In contrast, moderate to considerable acanthosis, with thickening and elongation of the rete ridges, contained many vacuolated cells of the stratum malpihii in $36 \mathrm{CA}$ samples. These CA samples did not show typical Bowenoid changes. The anogenital tumors had equivalent numbers of keratinocytes and/or dyskeratotic keratinocytes.

\section{Telomerase activity}

Epstein-Barr (EB) virus transformed B cell lines (Namalva cells) and normal skin were used as positive and negative control, respectively. All the normal control skin samples exhibited very low or absent TA when using the same amount of protein $(1 \mu \mathrm{g})$ for telomerase assay. In contrast, Namalva cells showed high TA and regarded as a 100\% relative TA value. Moderate to high TA levels were visualized in $41.7 \%$ (5 out of 12 ) BP samples when compared to CA $(p=0.025)$ and normal non sun-exposed skin $(p<$ 0.001). In contrast, $22.7 \%$ (5 out of 22) CA samples showed positive TA compared to normal non sunexposed skin $(p<0.001)$ (Figure 1). Among anogenital tumors, high TA levels corresponding to greater than $40 \%$ of relative TA were detected in 25\% (3 out of 12) BP samples, but none of the $22 \mathrm{CA}$ samples.

\section{Detection of low risk or high risk of HPV DNA}

Available10 BP and $10 \mathrm{CA}$ samples were examined to determine the presence of HPV DNA by performing the PCR assay. Low risk type HPV 6 was detected in all of the CA samples, while high risk types HPV 16 and HPV 31 were detected in $9 \mathrm{BP}$ samples and $1 \mathrm{BP}$ sample, respectively.

\section{C-IAP1, C-IAP2 and XIAP mRNA expression}

c-IAP1, c-IAP2, and XIAP were significantly upregulated in the BP samples compared to 15 CA samples (c-IAP1, $p$ $<0.001$; c-IAP2, $p<0.001$; XIAP, $p=0.022$; Figure 2A, B,

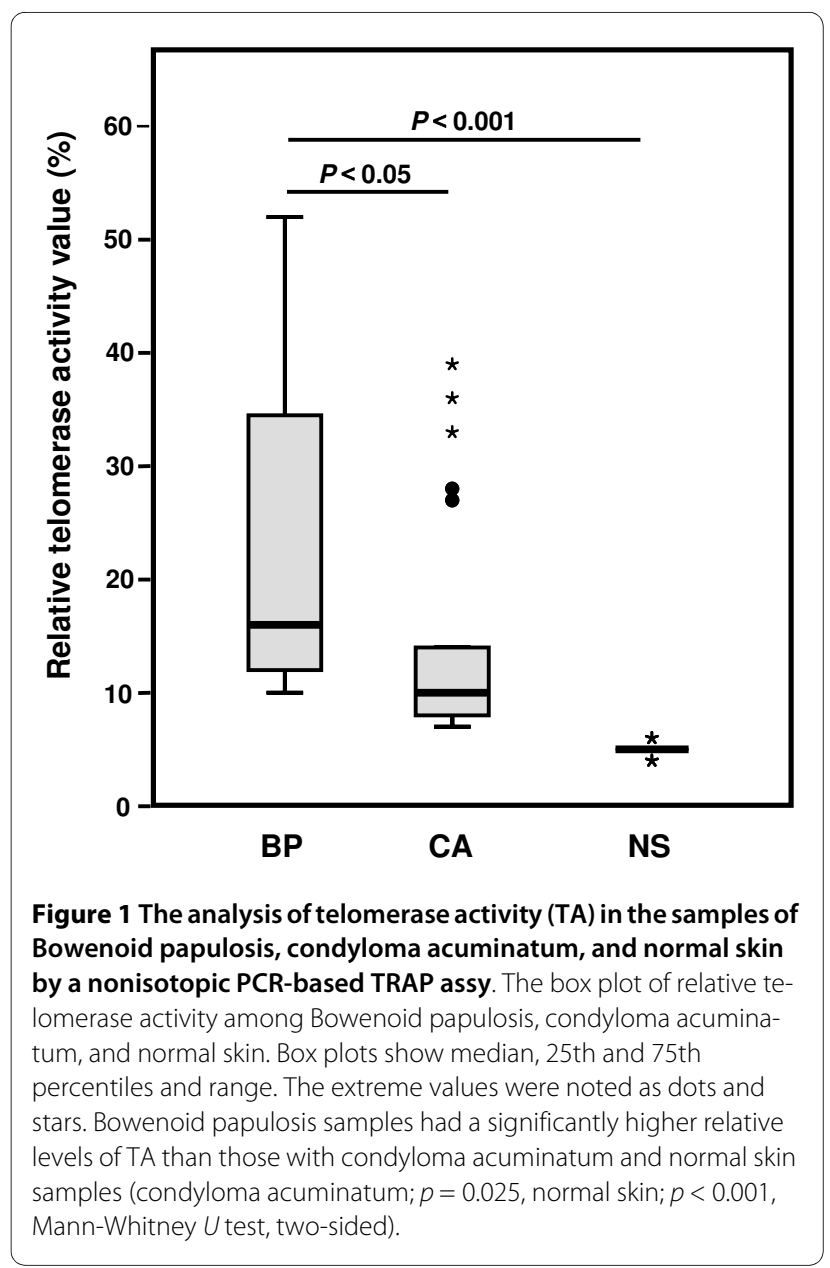

C). Similarly, c-IAP1, c-IAP2, and XIAP mRNA levels in BP samples were significantly up-regulated compared to NS (c-IAP1, $p<0.001$; c-IAP2, $p=0.002$; XIAP, $p=$ $0.034)$. To estimate the mRNA expression of the IAPs family, each BP sample was carefully examined in triplicate. Three of $10 \mathrm{BP}$ cases (Cases 6, 7 and 10) showed a higher expression level of the IAP family members compared to other samples (vs. other BP $(n=7)$; c-IAP1, $p<$ 0.001; c-IAP2, $p<0.001$; XIAP, $p<0.001$; and vs. CA $(n=$ 15); c-IAP1, $p<0.001$; c-IAP2, $p<0.001$; XIAP; $p<$ $0.001)$.

Although more than $27.3 \%$ of CA samples demonstrated positive TA, c-IAP1, c-IAP2, and XIAP expression levels were not significantly up-regulated when compared to the high expression levels observed in BP. This results suggested that the oncogenic proteins expressed by lowrisk HPV types did not activate c-IAP1, c-IAP2 or XIAP. The expression levels of c-IAP1, c-IAP2 and XIAP in CA were similar to the levels seen in NS (c-IAP1, $p=0.052$; cIAP2, $p=0.876$; XIAP, $p=0.098$ ). Two of 15 CA samples (Cases 12 and 13) demonstrated an increased expression of only XIAP compared to NS samples, but this expression was a rare event in other CA samples. 
A

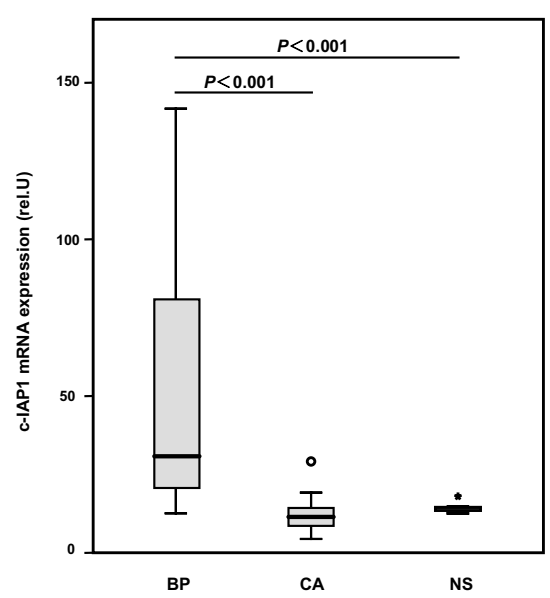

C

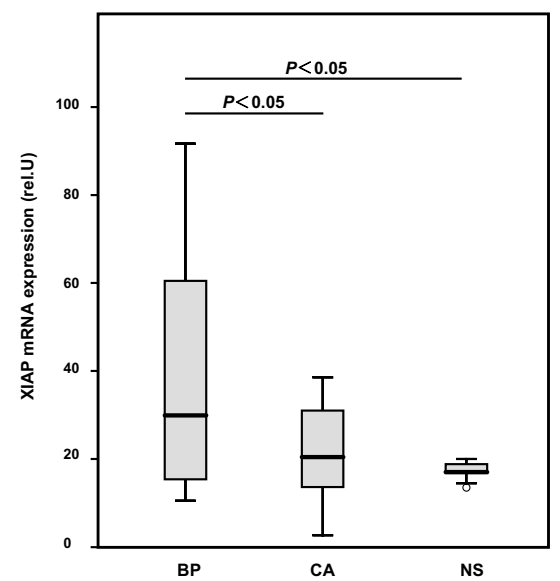

$\mathrm{B}$

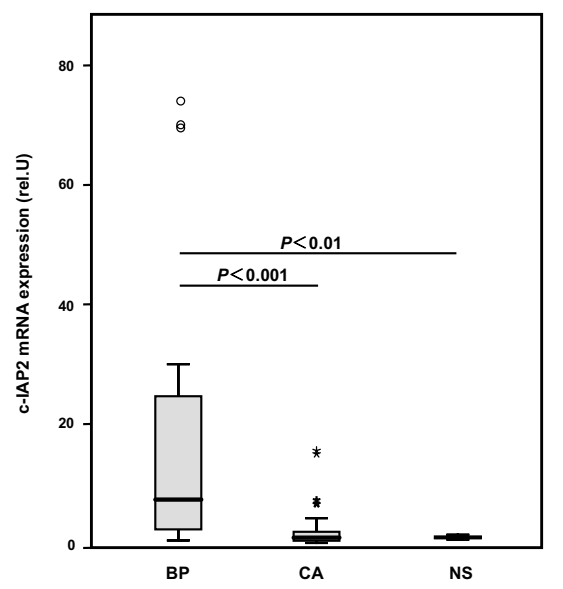

D

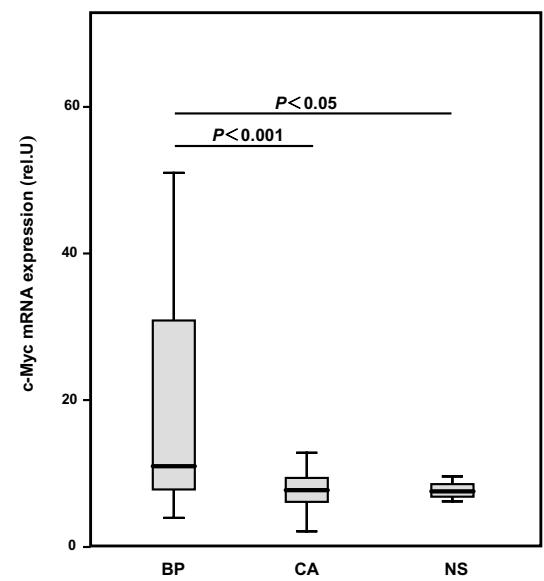

Figure 2 Quantitative real time RT-PCR analysis of (A) C-IAP1 (B) c-IAP2, (C) XIAP and (D) c-Myc in Bowenoid papulosis, condyloma acuminatum, and normal skin. The relative expression was calculated as the expression of the IAPs or c-Myc normalised to the expression of GAPDH. Each experiment was performed three times, and data are shown as box and whisker plots. The expression of (A) C-IAP1, (B) C-IAP2, (C) XIAP and (D) c-Myc was significantly higher in Bowenoid papulosis compared with condyloma acuminatum and normal skin. (A; condyloma acuminatum; $p<0.001$, normal skin; $p<0.001 \mathbf{B}$; condyloma acuminatum; $p<0.001$, normal skin; $p=0.002 \mathbf{C}$; condyloma acuminatum; $p=0.022$, normal skin; $p=0.034 \mathbf{D}$; condyloma acuminatum; $p<0.001$, normal skin; $p=0.01$, Mann-Whitney $U$ test, two-sided). In contrast, no significant difference in the expression of the IAP family members or c-Myc was detected between condyloma acuminatum and normal skin.

\section{C-Myc mRNA expression}

c-Myc mRNA expression showed significant differences between BP and CA samples ( $p<0.001$; Figure 2D). Similar to above, all measurements were performed in triplicate. Of $10 \mathrm{BP}$ and $15 \mathrm{CA}$ samples examined, 3 BP cases (Cases 6, 7 and 10) had significantly higher c-Myc expression compared to other samples (vs. other BP $(n=7)$; cMyc, $p<0.001$; and vs. CA $(n=15)$; c-Myc, $p<0.001)$. These three cases also showed higher expression levels of
c-IAP1, c-IAP2 and XIAP mRNA, suggesting the potential for a high level of malignancy. These results are consistent with those of a previous study, which suggested that HPV E6 directly interacts with $\mathrm{c}-\mathrm{Myc}$ and that cMyc/E6 complex activates hTERT expression [11]. Similar to the levels of c-IAP1, c-IAP2 and XIAP, mRNA expression level of $\mathrm{c}-\mathrm{Myc}$ was elevated in BP compared to NS samples $(p=0.010)$. In contrast, c-Myc expression in CA was similar to that of NS $(p=1.000)$. 


\section{P-Akt 308, P-S6 and P-4EBP-1 expression}

p-Akt expression was observed in the cytoplasm and nucleus of the intraepidermal cells (Figure 3A), while p4EBP1 expression was mainly observed in the nucleus of intraepidermal cells (Figure 3B) and p-S6 expression was predominantly observed in the cytoplasm or at the edge of the nucleus (Figure 3C). The expression percentage was based on the estimated number of intraepidermal cells in each tissue section with positive staining, either in the nucleus or cytoplasm. Of 34 cases examined, BP and CA specimens with TA clearly demonstrated an increased incidence of both p-Akt expression (Figure 4A) and $\mathrm{p}-\mathrm{S} 6$ expression (Figure 4B) compared to those samples without TA. In contrast, $\mathrm{p}-4 \mathrm{EBP} 1$ expression was not different between the anogenital tumors with or without TA (Figure 4C). Non sun-exposed normal skin demonstrated weak and occasionally moderate staining that was primarily localized to the basal layer (data not shown). In summary, there are differences in p-Akt308 and p-S6 expression, but not $\mathrm{p}-4 \mathrm{EBP} 1$ expression, between anogenital tumors with and without TA.

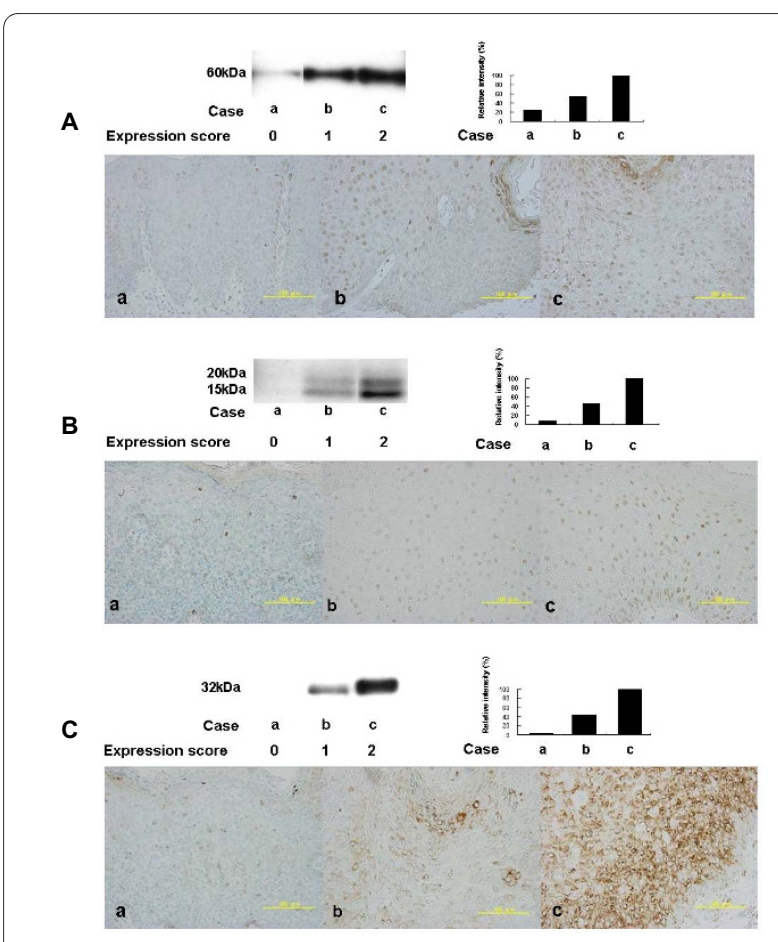

Figure 3 Western blot analysis and immunohistochemical analysis for P-Akt thr308 (A), P-4EBP1 (B) and P-S6 (C) in Bowenoid papulosis and condyloma acuminatum. Western blot validation of immunohistochemical stainings showed a good correlation. Cases b and $\mathrm{c}$ which exhibited more than 30\% expressions of $\mathrm{p}-\mathrm{Akt}$ thr 308 and p-S6, showed the intensity bands using frozen samples. In contrast, more than $30 \%$ expression of p-4EBP1 was detected, with double bands at 15 and $20 \mathrm{kDa}$ in Cases $\mathrm{b}$ and $\mathrm{c}$. The expression score indicates $0,>30 \% ; 1,30 \%$ to $60 \% ; 2,>60 \%$. Scale bars $=100 \mu \mathrm{m}$.

\section{Discusssion}

Although a broad range of malignancies was investigated, telomerase activity (TA) of a comparative study has not been reported in Bowenoid papulosis (BP) and condyloma acuminatum (CA) of anogenital tumors. Despite of the infection with high risk HPV, BP sometimes shows spontaneous regressions within a few months. However, BP may transform into squamous cell carcinoma (SCC) of the genitalia but the mechanism for the development of SCC from BP has not been defined [8]. In contrast, CA is also infected with HPV which is low risk HPV types 6 or 11. Overall, giant CA is occationally considered a low grade of SCC [8]. The BP and CA are little known regarding the molecular mechanisms involved in malignant transformation or spontaneous remission based on the biological alterations of the cell cycle, cell signaling and apoptosis.

In order to identify if HPV is associated with TA in BP and $\mathrm{CA}$ of anogenital tumors, samples were tested by TRAP assay. The typical ladder pattern was detected. Positive TA was detected in 41.7\% (5 of 12) BP samples and $22.7 \%$ (5 of 22) CA samples $(p=0.025)$. These results suggest that higher telomerase activity is correlated with high risk HPV associated BP compared to low risk HPV associated CA. There was no evidence of increased TA in normal skin (NS) from non-sun-exposed areas. Initially, we hypothesised that increased TA could be an important tumor marker for malignant potential. As expected, this study showed a higher frequency of increased TA in BP compared with CA. Importantly, increased TA was also found in $22.7 \%$ (5 out of 22) CA samples that were associated with low-risk HPV. In general, low levels of TA are present in non-malignant skin conditions [6]. Hiyama et al. demonstrated that leukocytes constitutively express low levels of TA [31]. Therefore, this study suggested that CA with TA may be an intermittent phenomenon and that the presence of low risk HPVs was not associated with increased TA. Overall, current study suggested that only the high risk HPV E6 and E7 genes increased TA in anogenital tumors.

The expression of the c-Myc gene is important for cell proliferation in HPV associated cutaneous lesions. The cMyc gene acts directly or indirectly through its interaction with p53 and E6 oncoproteins, and plays an important role for the induction of hTERT protein [9]. In contrast, IAPs family (XIAP, c-IAP1 and c-IAP2) can suppress apoptosis induced by a variety of apoptotic triggers. The IAPs family can inhibit the downstream components of caspase activation pathways that regulate apoptosis. Some studies have established a circumstantial association between the IAPs family and cancer. The overexpression of several family members has been detected in several classes of human cancers [32,33]. Among IAPs family, c-IAP2 is related to the hTERT protein and pro- 
A

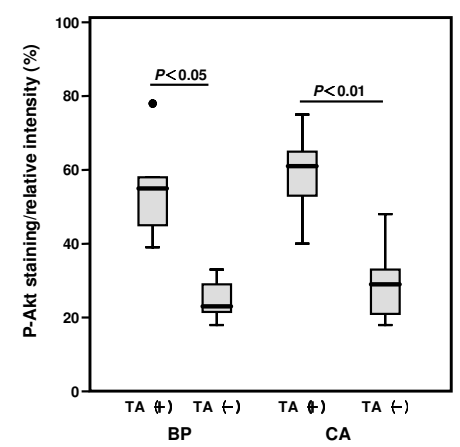

B

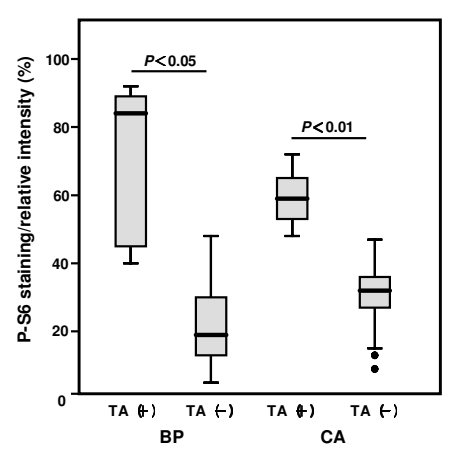

C

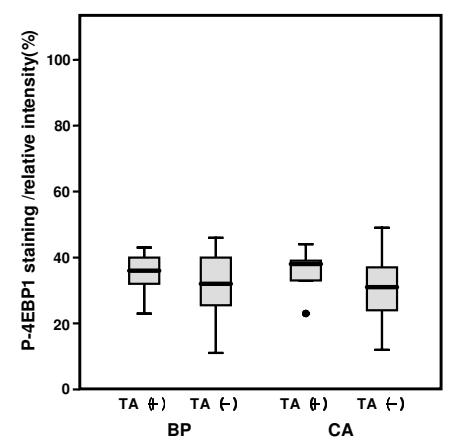

Figure 4 P-Akt thr308, P-S6 and P-4EBP1 expressions in relation with telomerase activity. Box graphs comparing positive telomerase activity (TA) for (A) P-Akt thr308, (B) P-S6 and (C) P-4EBP1 expressions in Bowenoid papulosis with and without TA $(\mathbf{A} ; p=0.004, \mathbf{B} ; \mathbf{P}=0.012, \mathbf{C} ; p=0.807, \mathbf{M a n n -}$ Whitney $U$ test, two-sided) and in condyloma acuminatum with and without TA $(\mathbf{A} ; p=0.001, \mathbf{B} ; p=0.001, \mathbf{C} ; p=0.307, \mathbf{M a n n}-$ Whitney $U$ test, twosided).

motes hTERT expression [22]. According to one study, overexpression of E6/E7 was found in high risk types HPV 16 and 18, but not in low risk type HPV 6, and an activated c-IAP2 promoter was found in E6/E7-immortalized human keratinocytes [22]. We quantitated the expression of IAPs family and c-Myc mRNA using real time RT-PCR assay in $10 \mathrm{BP}$ and $15 \mathrm{CA}$ samples. The levels of IAPs family members (c-IAP1, c-IAP2 and XIAP) and $\mathrm{c}-\mathrm{Myc}$ mRNA expression in BP samples were higher than those in CA and normal skin samples (Figure 2). The mRNA expression levels were carefully determined by performing triplicate assays. Of interest, 30\% (Cases 6, 7 and 10) of BP showed significantly high expression of cIAP1, c-IAP2 and XIAP genes compared to the other samples. Increased c-Myc expression was also found in $30 \%$ (Cases 6, 7, and 10) of BP, and was not observed in CA samples. These results supported that some BP with high risk HPV types have high levels of antiapoptosis, while CA does not have such characteristics. In Cases 6, 7 and 10, it would be necessary to remove the lesional skin, because BP may undergo transformation into SCC. In contrast, the low expression of mRNA IAPs family members in other BP and CA samples suggested limited cell proliferation and a possible tendency toward spontaneous remission.

The phophatidylinositol-3 kinase (PI3K)/Akt signaling pathway plays a central role in diverse cellular functions, including proliferation, growth, survival and metabolism. In general, Akt promotes protein synthesis and cell growth by alleviating TSC $1 / 2$ suppression of the mammalian target of rapamycin (mTOR), allowing the latter to act as part of the mTOR-raptor complex on 4E-binding protein 1 (4EBP1) and ribosomal protein S6 (S6) [34]. Both 56 and p70S6 kinase1 are present downstream in the Akt signaling pathway, which is not linearly associ- ated with 4EBP1 phosphorylation [35]. To date, alterations of the Akt/mTOR pathway have been observed in numerous types of carcinomas, but little has been reported about Akt/mTOR signaling in skin tumors. In the current study, although $\mathrm{p}-4 \mathrm{EBP} 1$ expression did not differ between CA and BP with or without positive TA, pAkt and p-S6 were expressed significantly more often in $\mathrm{BP}$ and CA with increased TA than in CA and BP without TA. This result suggested that positive TA is associated with activated p-Akt and p-S6 expression but not with p4EBP1 expression. Overall, we speculated that HPV associated anogenital tumor cells with increased TA could be correlated with activation of Akt/mTOR/p70S6K1/S6 signaling pathway but not with 4EBP1 signaling pathway. In fact, S6 and 4EBP1 are located in the downstream of Akt but they are different signal pathways [34,35].

\section{Conclusion}

Our study showed there were differences between TA levels in BP and CA of anogenital tumors. A minority of BP samples with high risk HPV types showed increased c-Myc and IAPs family mRNA expression, whereas CA samples with low risk HPV types showed little increase in those genes. These results provided the majority of CA even if they have increased TA and/or positive proteins expression in cell signaling pathway, this may be transient or intermittent phenomenon and may be indicative of future apoptosis. The majority of BP lesions in this study showed low levels of TA and mRNA expression of IAPs family and c-Myc, suggesting most of BP were considered to be less aggressive tumors. However, BP with high TA levels and increased mRNA expression of IAPs family and c-Myc may develop into SCC. Therefore, overexpression of IAPs family and c-Myc are also important in affecting cancer progression. Combined estimation of cell 
growth and apoptosis-regulating proteins may provide clinically relevant molecular markers in HPV associated anogenital tumors.

\section{Abbreviations}

TA: telomerase activity; HPVs: human papillomaviruses; c-IAPs: cellular inhibitor of apoptosis proteins; real time RT-PCR: real time reverse transcription polymerase chain reaction; p-Akt: phosphorylated Akt; S6: ribosomal protein S6; 4EBP1: 4E-binding protein 1; SCC: squamous cell carcinoma; BP: Bowenoid papulosis; CA: condyloma acuminatum; NS: normal skin.

\section{Competing interests}

The authors declare that they have no competing interests.

\section{Authors' contributions}

TM, TK, KO, and SK collected and analyzed clinical and pathological data, including patients' follow up. FO, and YY performed laboratory work and helped with data analysis. TM, KT, YI, TS, IO, KO, MN, and OY performed laboratory work, evaluated gene and protein expression, immunohistochemistry, and statistical analysis. TM, and OY wrote the manuscript. All the authors revised and approved the final version.

\section{Acknowledgements}

This work was supported by the Program for Promoting the Establishment of Strategic Research Centers, Special Coordination Funds for promoting Science and Technology, and Ministry of Education, Culture, Sports, Science and Technology (Japan).

\section{Author Details}

'Department of Dermatology, Nippon Medical School, 1-1-5 Sendagi, Bunkyou-ku, Tokyo, 113-8603, Japan, 2Department of Pathology, National Institute of Infectious Diseases, Toyama 1-23-1, Shinjuku-ku, Tokyo 162-8640, Japan, ${ }^{3}$ Department of Dermatology, The Fraternity Memorial Hospital, 2-1-11 Yokoami, Sumida-ku, Tokyo, 130-8587, Japan, ${ }^{4}$ Department of Dermatology, Toranomon Hospital, 2-2-2 Toranomon, Minato-ku, Tokyo, 105-8470, Japan, ${ }^{5}$ Department of Biochemistry and Cell Biology, Institute of Development and Aging Sciences, Graduate School of Medicine, Nippon Medical School, 1-396 Kosugi-cho, Nakahara-ku, Kawasaki City 211-8533, Japan and ${ }^{6}$ Department of Hematology, Tokyo Women's Medical University, 8-1 Kawada-cho, Shinjyukuku, Tokyo, 162-8666, Japan

Received: 18 August 2009 Accepted: 27 March 2010

Published: 27 March 2010

\section{References}

1. Yamada O, Oshimi K, Motoji T, Mizoguchi H: Telomeric DNA in normal and leukemic blood cells. J Clin Invest 1995, 95:1117-1123.

2. Bearss DJ, Hurley LH, Von Hoff DD: Telomere maintenance mechanisms as a target for drug development. Oncogene 2000, 19:6632-41.

3. Kawauchi K, Ihjima K, Yamada O: IL-2 increases human telomerase reverse transcriptase activity transcriptionally and posttranslationally through phosphatidylinositol 3'-kinase/Akt, heat shock protein 90, and mammalian target of rapamycin in transformed NK cells. J Immunol 2005, 174:5261-5269.

4. Mergny JL, Riou JF, Mailliet P, Teulade-Fichou MP, Gilson E: Natural and pharmacological regulation of telomerase. Nucleic Acids Res 2002, 30:839-65.

5. Yamada O, Ozaki K, Nakatake M, Akiyama M, Kawauchi K, Matsuoka R: Multistep regulation of telomerase during differentiation of $\mathrm{HL} 60$ cells. J Leukoc Biol 2008, 83:1240-1248.

6. Parris CN, Jezzard S, Silver A, MacKie R, McGregor JM, Newbold RF: Telomerase activity in melanoma and non-melanoma skin cancer. $\mathrm{Br} J$ Cancer 1999, 79:47-53.

7. Dong CK, Masutomi K, Hahn WC: Telomerase: regulation, function and transformation. Crit Rev Oncol Hematol 2005, 54:85-93.

8. Majewski S, Jablonska S: Human papillomavirus-associated tumors of the skin and mucosa. J Am Acad Dermatol 1997, 36:659-685.

9. Rolighed J, Sørensen IM, Jacobsen NO, Lindeberg H: The presence of HPV types 6/11, 13, 16 and 33 in bowenoid papulosis in an HIV-positive male, demonstrated by DNA in situ hybridization. APMIS 1991, 99:583-585.

10. Pala S, Poleva I, Vocatura A: The presence of HPV types $6 / 11,16 / 18,31 /$ 33/51 in Bowenoid papulosis demonstrated by DNA in situ hybridization. Int J STD AIDS 2000, 11:823-824.

11. Veldman T, Liu X, Yuan H, Schlegel R: Human papillomavirus E6 and Myc proteins associate in vivo and bind to and cooperatively activate the telomerase reverse transcriptase promoter. Proc Natl Acad Sci USA 2003, 100:8211-8216.

12. Rojo F, Najera L, Lirola J, Jiménez J, Guzmán M, Sabadell MD, Baselga J, Ramon y Cajal S: 4E-binding protein 1, a cell signaling hallmark in breast cancer that correlates with pathologic grade and prognosis. Clin Cancer Res 2007, 13:81-89.

13. Toker A, Yoeli-Lerner M: Akt signaling and cancer: surviving but not moving on. Cancer Res 2006, 66:3963-3966.

14. Blume-Jensen P, Hunter T: Oncogenic kinase signaling. Nature 2001, 411:355-365.

15. Heesom KJ, Gampel A, Mellor H, Denton RM: Cell cycle-dependent phosphorylation of the translational repressor elF-4E binding protein1 (4E-BP1). Curr Biol 2001, 11:1374-1379.

16. Topisirovic I, Ruiz-Gutierrez M, Borden KL: Phosphorylation of the eukaryotic translation initiation factor elF4E contributes to its transformation and mRNA transport activities. Cancer Res 2004, 64:8639-8642.

17. Kasof GM, Gomes BC: Livin, a novel inhibitor of apoptosis protein family member. J Biol Chem 2001, 276:3238-3246.

18. Tamm I, Richter S, Scholz F, Schmelz K, Oltersdorf D, Karawajew L, Schoch C, Haferlach T, Ludwig WD, Wuchter C: XIAP expression correlates with monocytic differentiation in adult de novo AML: impact on prognosis. Hematol J 2004, 5:489-495

19. Yang $L, C a o$ Z, Yan H, Wood WC: Coexistence of high levels of apoptotic signaling and inhibitor of apoptosis proteins in human tumor cells: implication for cancer specific therapy. Cancer Res 2003, 63:6815-6824

20. Liu SS, Tsang BK, Cheung AN, Xue WC, Cheng DK, Ng TY, Wong LC, Ngan $\mathrm{HY}$ : Anti-apoptotic proteins, apoptotic and proliferative parameters and their prognostic significance in cervical carcinoma. Eur J Cancer 2001, 37:1 104-1110.

21. Espinosa M, Cantu D, Herrera N, Lopez CM, De la Garza JG, Maldonado V Melendez-Zajgla J: Inhibitors of apoptosis proteins in human cervical cancer. BMC Cancer 2006, 6:1-10.

22. Yuan H, Fu F, Zhuo J, Wang W, Nishitani J, An DS, Chen IS, Liu X: Human papillomavirus type $16 \mathrm{E} 6$ and $\mathrm{E} 7$ oncoproteins upregulate c-IAP2 gene expression and confer resistance to apoptosis. Oncogene 2005, 24:5069-5078.

23. Nakatake M, Sasaki N, Murakami-Murofushi K, Yamada O: Transient posttranslational up-regulation of telomerase activity during megakaryocytic differentiation of K562 cells. Biochem Biophys Res Commun 2004, 31:1080-1085.

24. Yamada O, Akiyama M, Kawauchi K, Adachi T, Yamada H, Kanda N, Aikawa E: Overexpression of telomerase confers a survival advantage through suppression of TRF1 gene expression while maintaining differentiation characteristics in K562 cells. Cell Transplant 2003, 12:365-377.

25. Nakatake M, Kakiuchi Y, Sasaki N, Murakami-Murofushi K, Yamada O: STAT3 and PKC differentially regulate telomerase activity during megakaryocytic differentiation of $\mathrm{K} 562$ cells. Cell Cycle 2007, 6:1496-1501.

26. Kinomoto M, Kanno T, Shimura M, Ishizaka Y, Kojima A, Kurata T, Sata T, Tokunaga K: All APOBEC3 family proteins differentially inhibit LINE-1 retrotransposition. Nucleic Acids Res 2007, 35:2955-2964.

27. Nagata N, Iwata N, Hasegawa H, Fukushi S, Harashima A, Sato Y, Saijo M, Taguchi F, Morikawa S, Sata T: Mouse-passaged severe acute respiratory syndrome-associated coronavirus leads to lethal pulmonary edema and diffuse alveolar damage in adult but not young mice. Am J Pathol 2008, 172:1625-1637.

28. Tsuji A, Wakisaka N, Kondo S, Murono S, Furukawa M, Yoshizaki T: Induction of receptor for advanced glycation end products by EBV latent membrane protein 1 and Its correlation with angiogenesis and cervical lymph node metastasis in nasopharyngeal carcinoma. Clin Cancer Res 2008, 14:5368-5375.

29. Mitsuishi T, Sata T, Matsukura T, Iwasaki T, Kawashima M: The presence of mucosal human papillomavirus in Bowen's disease of the hands. Cancer 1997, 79:1911-1917. 
30. Yoshikawa H, Kawana T, Kitagawa K, Mizuno M, Yoshikura H, Iwamoto A: Detection and typing of multiple genital human papillomaviruses by DNA amplification with consensus primers. Jpn J Cancer Res 1991, 82:524-531.

31. Hiyama K, Hirai Y, Kyoizumi S, Akiyama M, Hiyama E, Piatyszek MA, Shay JW, Ishioka S, Yamakido M: Activation of telomerase in human lymphocytes and hematopoietic progenitor cells. J Immunol 1995, 155:3711-3715

32. Schimmer AD: Inhibitor of apoptosis proteins: translating basic knowledge into clinical practice. Cancer Res 2004, 64:7183-7190.

33. Nachmias B, Ashhab Y, Ben-Yehuda D: The inhibitor of apoptosis protein family (IAPs): an emerging therapeutic target in cancer. Semin Cancer Biol 2004, 14:231-243.

34. Serra V, Markman B, Scaltriti M, Eichhorn PJ, Valero V, Guzman M, Botero ML, Llonch E, Atzori F, Di Cosimo S, Maira M, Garcia-Echeverria C, Parra JL, Arribas J, Baselga J: NVP-BEZ235, a dual PI3K/mTOR inhibitor, prevents $\mathrm{PI} 3 \mathrm{~K}$ signaling and inhibits the growth of cancer cells with activating PI3K mutations. Cancer Res 2008, 68:8022-8030.

35. Hara K, Yonezawa K, Weng QP, Kozlowski MT, Belham C, Avruch J: Amino acid sufficiency and mTOR regulate p70 S6 kinase and elF-4E BP1 through a common effector mechanism. J Biol Chem 2007, 273:14484-14494.

\section{Pre-publication history}

The pre-publication history for this paper can be accessed here: http://www.biomedcentral.com/1471-2407/10/118/prepub

doi: 10.1186/1471-2407-10-118

Cite this article as: Mitsuishi et al., Combined analysis of cell growth and apoptosis-regulating proteins in HPVs associated anogenital tumors BMC Cancer 2010, 10:118

Submit your next manuscript to BioMed Central and take full advantage of:

- Convenient online submission

- Thorough peer review

- No space constraints or color figure charges

- Immediate publication on acceptance

- Inclusion in PubMed, CAS, Scopus and Google Scholar

- Research which is freely available for redistribution

Submit your manuscript at www.biomedcentral.com/submit
C) Biomed Central 